\title{
Application of Rheo-diecasting of a High Strength Al-Si-Mg Alloy to Automotive Suspension Arms
}

\author{
Byoung Hee $\mathrm{CHOI},{ }^{1)}$ Young Soo JANG, ${ }^{1)}$ Jae Gi SIM, ${ }^{2)}$ Hae Su KIM ${ }^{3)}$ and Chun Pyo HONG ${ }^{1 *}$ \\ 1) Center for Computer-Aided Solidification Processing (CASP), Dept. of Metallurgical Engineering, Yonsei University, \\ Shinchon-dong 134, Seodaemun-ku, Seoul, 120-749 Korea. \\ 2) Metallic Materials Research Team, Hyundai-Kia Motors, 772-1 Jangduk-Dong, Hwaseong-Si, Gyeonggi-Do, $445-706$ Korea. \\ 3) Module Research Team, Hyundai Wia co., 462-18 Sam-Dong, Uiwang-Si, Gyeonggi-Do, 437-812 Korea.
}

(Received on November 19, 2012; accepted on December 18, 2012)

\begin{abstract}
A rheo-diecasting using a high-strength Al alloy has been investigated to estimate its applicability to the manufacturing of automobile suspension parts to replace the hot-forging process. The alloy used in the present study was based on the Al-Si-Mg system, which was developed recently for high mechanical performance in rheo-diecasting. Two important aspects were considered in this effort to use rheo-diecasting in practical applications: (i) optimization of the manufacturing conditions for semi-solid slurries and (ii) a proper mold design for rheo-diecasting. Electromagnetic stirring of the melt was carried out to obtain high-quality slurries. Two types of gating systems were considered: the vertical gate type and the horizontal gate type. A horizontal type of gating system with an injection velocity of $0.5-1.5 \mathrm{~m} / \mathrm{s}$, as designed using computer simulation of the fluid flow, was successfully applied to the rheo-diecasting of tension arms. X-ray inspection and microstructure observation were carried out to analyze the formation of casting defects. No defects, such as shrinkage porosity and eutectic segregation, were found in the rheo-diecast products. An evaluation of the rheo-diecast tension arms was carried out through a tensile test, a durability test and assembled module tests. The rheo-diecast products showed significant improvements in their tensile properties, such as the yield strength of $281 \mathrm{MPa}$, the tensile strength of $331 \mathrm{MPa}$, and the elongation of $11.8 \%$, which are superior to those values of high pressure diecasting products. In the durability and assembled module tests, the rheo-diecast tension arms satisfied the specifications of hot-forged tension arms.
\end{abstract}

KEY WORDS: semi-solid; rheo-diecasting; electromagnetic stirring; automotive parts; mechanical properties; tension arm.

\section{Introduction}

Recently, automotive parts made of cast iron and steel have been replaced with parts made of aluminum alloys. ${ }^{1)}$ Numerous aluminum components have been manufactured using high pressure diecasting (HPDC) owing to its high productivity and dimensional accuracy. However, the mechanical properties of automotive parts manufactured by the HPDC process are lacking in terms of mechanical properties. Heat treatments for improving the mechanical performance cannot be carried out due to the formation of blisters and various inner defects, such as gas porosity and shrinkage. ${ }^{2)}$ Rheo-diecasting is known as an alternative process capable of replacing HPDC for the manufacturing of highstrength aluminum components. ${ }^{3-5)}$ The mechanical properties of aluminum components produced by rheo-diecasting, which have fine and uniform microstructures with low gas defects, can be improved by a T6 heat treatment. ${ }^{6,7)}$

Typical aluminum alloys used in the rheo-diecasting process are based on the Al-Si system, such as AC4C and

* Corresponding author: E-mail: hong@yonsei.ac.kr

DOI: http://dx.doi.org/10.2355/isijinternational.53.502
$\mathrm{ADC10}$, in which the Si amounts are in the range of 7-10 wt.\%, which ensures good castability. However, the large amounts of Si particles which form during the eutectic reaction can become a site of high stress intensity, resulting in the deterioration of the mechanical strength and elongation. ${ }^{8)}$ This alloy is limited when used for high mechanical performance in the automotive industry. Hot forging has been used as a typical method for the manufacturing of aluminum automotive components with superior mechanical properties compared to those of cast parts. With regard to productivity and production costs, the casting process is considered to be more effective than hot forging. There has been strong demand for the development of new alloys which offer high mechanical performance and which can be used with the rheo-diecasting process.

Recently, a new alloy based on the $\mathrm{Al}-\mathrm{Si}-\mathrm{Mg}$ system for rheo-diecasting with high mechanical properties was developed. ${ }^{9)}$ There are two important aspects to consider in order to use this new alloy in practical applications: (i) manufacturing high-quality semi-solid slurries and (ii) a proper design of the mold for rheo-diecasting based on fluidity and a solidification simulation. The mechanical properties of 
rheo-diecast products are closely related to the quality of the slurry, such as the fineness and uniformity of the $\alpha$-Al particles. In our previous studies, electromagnetic stirring was successfully applied to manufacture high quality semi-solid slurries using AC4C and ADC10 alloys, which have fine and globular $\alpha$-Al particles. ${ }^{10,11)}$

The new alloy developed in our previous study was based on $\mathrm{Al}-5.0 \mathrm{wt} \% \mathrm{Si}-0.7 \mathrm{wt} \% \mathrm{Mg}$ in order to improve the mechanical properties. The amount of Si is generally known to be closely related to the fluidity of semi-solid slurries in the die cavity during rheo-diecasting. Because the amount of $\mathrm{Si}$ in the new alloy is much lower than those of the $\mathrm{AC} 4 \mathrm{C}$ and ADC10 alloys, deterioration of the castability of the new alloy can be expected in rheo-diecasting. It is therefore necessary to optimize the injection velocity as well as the design of the gating system to improve the fluid flow in the die cavity. Casting defects, such as incomplete filling and micro-porosity, can be found when the injection velocity is not proper. ${ }^{12)}$ Furthermore, an improper die design may lead to the formation of shrinkage defects and eutectic segregation.

The objectives of the present study are to investigate the rheo-diecasting of a new alloy to manufacture automotive suspension arms and evaluate the possibility of its practical application to replace the hot-forging process. Optimization of the slurry-making conditions was carried out through cooling curve experiments and microstructural observations with and without electromagnetic stirring. A proper die design based on a computer simulation of the fluid flow and solidification was utilized to improve the castability and to prevent the formation of casting defects. An evaluation of the rheo-diecast tension arms was carried out through a durability test and assembly tests, specifically module durability and module impact tests. The results were estimated by a comparison with hot-forged tension arms.

\section{Experimental Procedure}

The composition of the alloy used in the present study is shown in Table 1. The alloy was melted and degassed at $700^{\circ} \mathrm{C}$ using pure Ar gas and a degassing chemical tablet

Table 1. The composition of present alloy for rheo-diecasting.

\begin{tabular}{lcccccccc}
\hline \multicolumn{1}{c}{ Composition (wt.\%) } & $\mathrm{Si}$ & $\mathrm{Mg}$ & $\mathrm{Cu}$ & $\mathrm{Fe}$ & $\mathrm{Mn}$ & $\mathrm{Zn}$ & $\mathrm{Ti}$ & $\mathrm{Al}$ \\
\hline Alloy used in present study & 5.0 & 0.7 & 0.5 & 0.15 & 0.1 & 0.3 & 0.05 & Bal. \\
AC4C & 7.0 & 0.3 & 0.2 & 0.2 & 0.1 & - & 0.05 & Bal. \\
6061 & 0.6 & 1.0 & 0.25 & 0.7 & 0.15 & 0.2 & 0.15 & Bal. \\
\hline
\end{tabular}

$\left(\mathrm{N}_{2}\right)$ and was held at $650 \pm 5^{\circ} \mathrm{C}$ for 30 min prior to making the slurry. The slurry-making system with EM stirring and the rheo-diecasting system integrated with HPDC used in the present study are shown in Figs. 1(a) and 1(b). ${ }^{13)}$ The slurry-making vessels, made of stainless steel coated with $\mathrm{BN}$, were $95 \mathrm{~mm}$ in diameter and $230 \mathrm{~mm}$ in length. The pouring temperature of the melt into the slurry-making vessel was $15^{\circ} \mathrm{C}$ above the liquidus temperature. The semi-solid slurry was taken out of the slurry-making vessel at the temperature which corresponds to the solid fraction of 0.4 . In order to determine and measure the solid fraction, firstly the relation between the solid fraction and temperature was estimated by Thermo-Calc. simulation, and secondly the cooling curve experiment was carried out in the slurry forming process. In our previous study, the slurry quality was optimized with various solid fractions, and it was found that the slurry with the solid fraction of 0.4 was optimum for rheo-diecasting. ${ }^{9)}$ In order to estimate the uniformity of the slurry, the temperature changes of the melt with time in the slurry vessel were measured at two positions: one at the center of the vessel $\left(\mathrm{T}_{\text {cen }}\right)$ and the other near the bottom-surface of the vessel $\left(\mathrm{T}_{\text {sur }}\right)$, as shown in Fig. 1(a). For the microstructural observation, all the samples were ground with $\mathrm{SiC}$ paper and polished on a cloth with a $0.04 \mu \mathrm{m}$ diamond suspension. The polished specimens were etched in the Keller's etchant $\left(950 \mathrm{~mL} \mathrm{H} \mathrm{H}_{2} \mathrm{O}+25 \mathrm{ml} \mathrm{HNO}_{3}+15 \mathrm{ml} \mathrm{HCl}+10 \mathrm{ml}\right.$ $\mathrm{HF})$. The microstructures were analyzed using an optical microscope fitted with a digital camera and an image analyzer.

To estimate the practical applicability of the new alloy, rheo-diecasting was carried out to manufacture tension arms using a 550-ton diecasting machine. In the rheo-diecasting process, the mold and sleeve were maintained at about $200^{\circ} \mathrm{C}$ using a heating system. When the slurry passes through the ingate, the injection velocity of the plunger was controlled in the range of $0.5-1.5 \mathrm{~m} / \mathrm{s}$. A computer simulation of the solidification and fluid flow during rheo-diecasting was carried out to predict casting defects and to design a proper gating system. ${ }^{14)}$ An X-ray analysis was carried out to estimate the quality of the rheo-diecast products. Hardness and tensile properties were measured and compared with those of the HPDC and hot-forged products. The hardness was measured using a Rockwell hardness tester (HRS150 ), and the tensile test was performed using a hydraulic Instron 8500 system. The durability, module durability and impact test were performed using specially designed testers in-house. The fracture surfaces of the tensile test specimens were also analyzed using SEM-EDS both for the HPDC and rheo-diecast tension arms. Finally, various tests, in this case

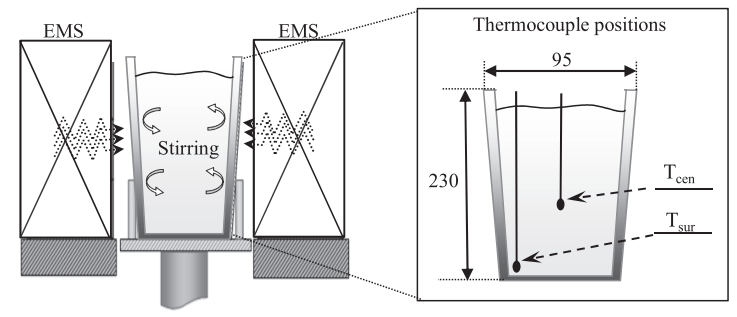

(a)

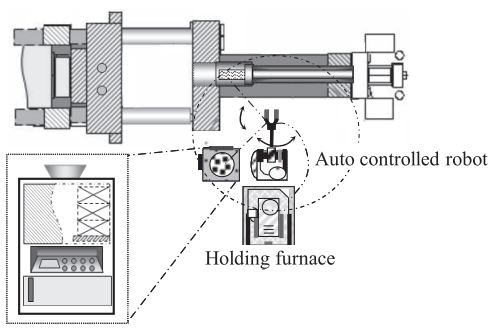

(b)

Fig. 1. Schematic drawings of (a) the slurry maker and the representative thermocouple positions in the slurry-making vessel and (b) rheo-diecasting system integrated with HPDC machine. 


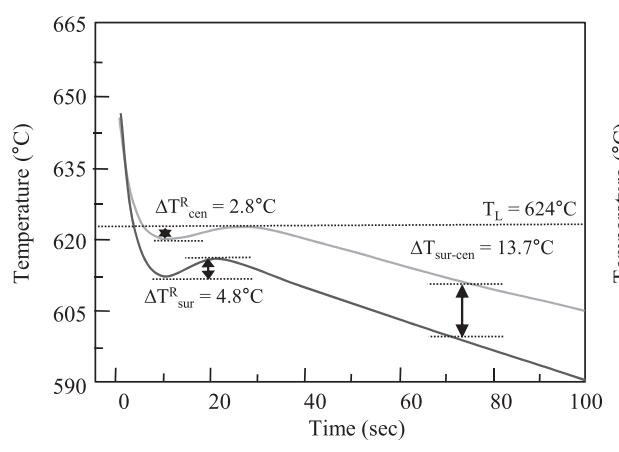

(a)

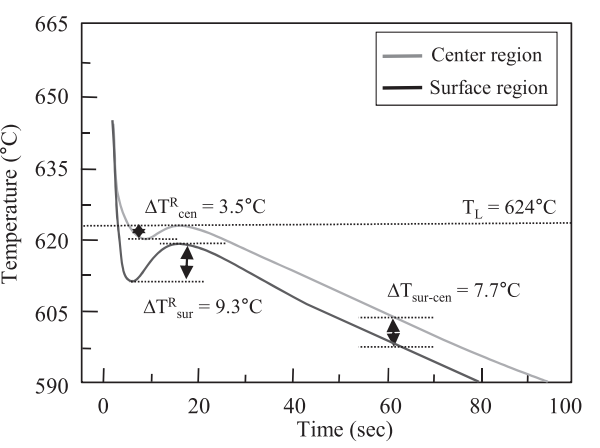

(b)

Fig. 2. The temperature-time curves in the cooling experiment at the center and the surface regions in the slurry-making vessel which (a) in the absence of EM stirring and (b) in the presence of EM stirring.

durability, module durability and module impact tests, were carried out on rheo-diecast tension arms and the results were compared with those of hot-forged 6061 tension arms in order to evaluate the practical applicability of the rheodiecast process.

\section{Results and Discussion}

\subsection{Effect of EM Stirring on a Semi-solid Slurry}

In rheo-diecasting, the quality of semi-solid slurries plays a key role in determining the castability of the slurry in the die cavity and the mechanical properties of the final rheodiecast products. ${ }^{10,13)}$ The quality of semi-solid slurries is closely related to the size and the density of the globular $\alpha$ Al particles, which are dependent on the stirring conditions and the size of the slurry-making vessel. In order to obtain fine and uniform globular microstructures, it is necessary to increase the number of heterogeneous nucleation sites and to control the temperature and solute fields uniformly in the melt during the formation of slurries. ${ }^{15)}$ In the present study, an electromagnetic (EM) stirring system is adopted to solve these problems.

In order to estimate the quality of the slurries using a slurry-making vessel (95 $\mathrm{mm}$ in diameter and $230 \mathrm{~mm}$ in length), as used for the practical application of rheo-diecasting in the present study, a cooling curve experiment during the solidification was carried out. These results are shown in Fig. 2, where (a) indicates the curve without EM stirring and (b) indicates the curve using EM stirring. The amount of heterogeneous nucleation can be estimated by the recalescence temperature, referred to as $\Delta \mathrm{T}^{\mathrm{R}}$, as caused by the latent heat of solidification. ${ }^{10)}$ As shown in Figs. 2(a) and 2(b), the recalescence temperatures on the bottom surface of the vessel $\left(\Delta \mathrm{T}_{\text {sur }}^{\mathrm{R}}\right)$ were larger than those at the center of the slurry vessel $\left(\Delta \mathrm{T}_{\text {cen }}^{\mathrm{R}}\right)$, and the $\Delta \mathrm{T}^{\mathrm{R}}$ sur with EM stirring was much larger than that without EM stirring. The uniformity of the slurry is also one of the most important factors in determining the quality of slurries. In order to estimate the uniformity of the slurries here, the temperature difference between the center and the bottom surface of slurry, denoted as $\Delta$ Tsur-cen, was measured at a solid fraction of 0.4 . In the absence of EM stirring, $\Delta \mathrm{T}_{\text {sur-cen }}$ was $13.7^{\circ} \mathrm{C}$. However, in the presence of $\mathrm{EM}$ stirring, $\Delta \mathrm{T}_{\text {sur-cen }}$ was $7.7^{\circ} \mathrm{C}$, which was lower than that in the absence of EM stirring. As the temperature difference in the slurry, $\Delta \mathrm{T}_{\text {sur-cen, }}$ decreases, the difference in the fraction solid

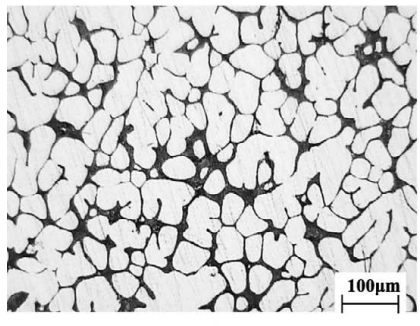

(a)

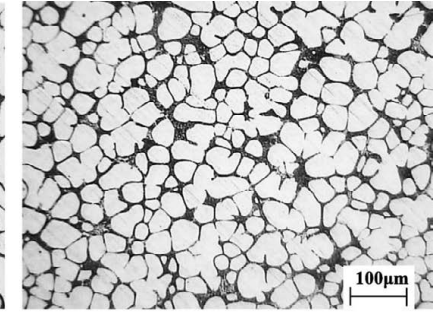

(b)
Fig. 3. Microstructures of the slurry obtained (a) in the absence of EM stirring and (b) in the presence of EM stirring.

in the slurry, $\Delta \mathrm{f}_{\mathrm{s}}$, decreases. Here, $\Delta \mathrm{f}_{\mathrm{s}}$ indicates the difference in the fraction solid between the center and the bottom surface of the slurry, which can be evaluated by $\Delta \mathrm{T}_{\text {sur-cen. }}$ This shows that heterogeneous nucleation on the surface of the vessel, which is related to the number of $\alpha$-Al particles, can be effectively enhanced by applying EM stirring.

The quality of semi-solid slurries for rheo-diecasting is determined by the morphology of the $\alpha$-Al particles, especially the size, globularity and density of these particles. The typical morphology of $\alpha$-Al particles without and with EM stirring is shown in Fig. 3. In the absence of EM stirring, as shown in (a), the $\alpha$-Al particles show a dendritic and rosette-like morphology and the size is coarse due to the non-uniform growth caused by the large value of $\Delta \mathrm{T}_{\text {sur-cen }}$ in the melt. However, in the presence of EM stirring, as shown in (b), the $\alpha$-Al particles become non-dendritic due to the decrease in $\Delta \mathrm{T}_{\text {sur-cen. }}$ In order to quantitatively estimate the microstructural characteristics of the $\alpha$-Al particles, the particle size and the form factor, referred to respectively as D and $\mathrm{F}$, were evaluated using the following equations: ${ }^{13)}$

$$
\begin{aligned}
& \mathrm{D}=\sqrt{4 \mathrm{~A} / \pi} \\
& \mathrm{F}=\mathrm{p}^{2} / 4 \pi \mathrm{A}
\end{aligned}
$$

Here, $\mathrm{A}$ and $\mathrm{p}$ are the area and perimeter of the $\alpha$-Al particles, respectively. The form factor $(\mathrm{F})$ is the index indicating the globularity of $\alpha$-Al particles. As the value F approaches to 1.0 , the globularity of $\alpha$-Al particles increases and theoretically becomes perfect when $\mathrm{F}$ is equal to 1.0. The microstructural characteristics of semi-solid slurries were evaluated using the above-mentioned formulas. The results are summarized in Table 2. The density of the $\alpha$-Al particles, as defined by the numberof $\alpha$-Al particles in an area of $1 \times 1$ 
Table 2. Quantitative analyses of microstructures of slurries with and without EM stirring.

\begin{tabular}{lccc}
\hline & \multicolumn{3}{c}{ Microstructural characteristics } \\
\cline { 2 - 4 } & Form factor & $\begin{array}{c}\text { Average size of } \\
\alpha \text {-Al particles } \\
(\mu \mathrm{m})\end{array}$ & $\begin{array}{c}\text { Density of } \\
\alpha \text {-Al particles } \\
\left(\text { counts } / \mathrm{mm}^{2}\right)\end{array}$ \\
\hline No EM stirring & 0.65 & 75 & $0.7 \cdot 10^{2}$ \\
EM stirring & 0.84 & 59 & $1.8 \cdot 10^{2}$ \\
\hline
\end{tabular}

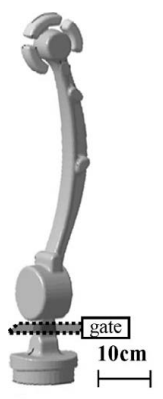

(a)

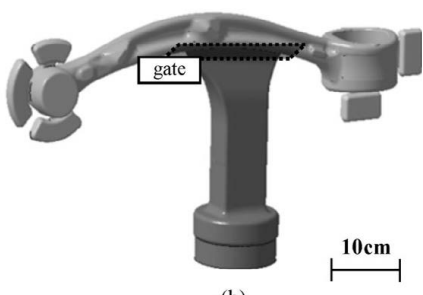

(b)
Fig. 4. Mold designs of tension arm for rheo-diecasting; (a) vertical-type gate and (b) horizontal-type gate.

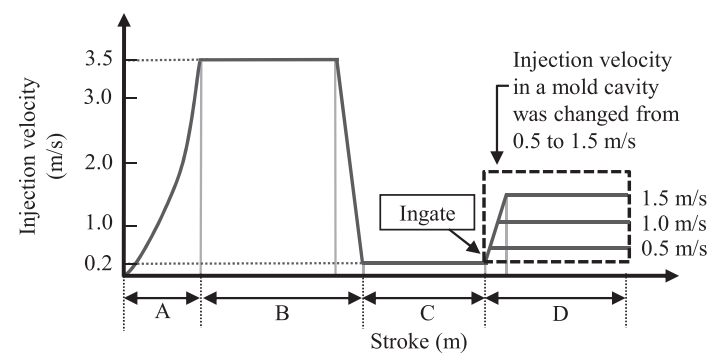

\begin{tabular}{ccc}
\hline Section & Stages & Objectives \\
\hline A & Initial accelated region & $\begin{array}{c}\text { Prevent the slurry } \\
\text { from the formation of blow hole }\end{array}$ \\
\hline B & High speed in the sleeve & $\begin{array}{c}\text { Prevent the slurry from the formation } \\
\text { of solidification shell in the sleeve }\end{array}$ \\
\hline C & $\begin{array}{c}\text { Stable feeding } \\
\text { before the ingate }\end{array}$ & $\begin{array}{c}\text { Prevent entrapment of air } \\
\text { into the mold cavity }\end{array}$ \\
\hline D & $\begin{array}{c}\text { Feeding stage in } \\
\text { the mold cavity }\end{array}$ & $\begin{array}{c}\text { Prevent the casting defects such as } \\
\text { misrun, cold shut, and shrinkage porosity }\end{array}$ \\
\hline
\end{tabular}

Fig. 5. Typical injection systems for the rheo-diecasting process.

$\mathrm{mm}^{2}$, was also estimated. As described in Table 2, the $\alpha$-Al particles become much more globular and finer with EM stirring. It is considered that the quality of semi-solid slurries for the new alloy can be effectively increased by EM stirring.

\subsection{Mold Design for Rheo-diecasting}

In order to estimate the application of the new alloy for the rheo-diecasting of automotive suspension parts, which require high mechanical performance, optimization of the mold and the injection velocity were investigated. The quality of the final rheo-diecast tension arm depends not only on the quality of the semi-solid slurries but also on the proper design of the mold and the injection velocity. Two types of gating systems were considered: a vertical-type gate and a horizontal-type gate, as shown in Fig. 4. In this study, the injection velocity was controlled during rheo-diecasting according to the concept shown in Fig. 5. ${ }^{13)}$ The injection
Table 3. Paramerters of slurry and ingate dimension to calculate Reynolds number.

\begin{tabular}{lccc}
\hline Parameters & Values & Unit \\
\hline Density of slurry $(\rho)$ & 2.68 & $\mathrm{~g} / \mathrm{cm}^{3}$ \\
Viscosity of slurry at $\mathrm{f}_{\mathrm{s}}=0.4(\mu)^{13)}$ & 0.75 & $\mathrm{~g} / \mathrm{cm} \mathrm{s}$ \\
$\begin{array}{l}\text { Ingate dimension } \\
(\text { width } \times \text { thickness })\end{array}$ & Vertical type & $500 \times 500$ & $\mathrm{~mm}$ \\
\hline
\end{tabular}

Table 4. Calculated results of Reynolds number on various mold designs and injection velocities in rheo-diecasting.

\begin{tabular}{clccc}
\hline \multirow{2}{*}{ Mold type } & Parameter & \multicolumn{3}{c}{ Injection velocity $(\mathrm{m} / \mathrm{s})$} \\
\cline { 3 - 5 } & & 0.5 & 1.0 & 1.5 \\
\hline \multirow{2}{*}{ Vertical Type } & Reynolds number (Re) & 893 & 1786 & 2680 \\
& Flow characteristics & larminar & larminar & transient \\
& Reynolds number (Re) & 484 & 968 & 1452 \\
Horizontal type & Flow characteristics & larminar & larminar & larminar \\
& & & &
\end{tabular}

velocity at stage A-B prior to the ingate was set at $3.5 \mathrm{~m} / \mathrm{s}$, higher than that of the other stages, in order to prevent initial solidification in the sleeve. The injection velocity at stage $\mathrm{C}$ when the slurry passes through the ingate was set at $0.2 \mathrm{~m} / \mathrm{s}$, which is much lower than that of the other stages, to prevent the entrapment of air into the mold cavity. Finally, the injection velocity at stage $\mathrm{D}$ is increased to prevent the casting defects such as misrun, cold shut, and shrinkage porosity. The effect of the injection velocity at stage D was investigated in the range of $0.5 \mathrm{~m} / \mathrm{s}-1.5 \mathrm{~m} / \mathrm{s}$.

The flow characteristics during the filling of a mold is related to the Reynolds number, which is dependent upon the injection velocity in stage D. The Reynolds number is calculated by the following equation: ${ }^{16)}$

$$
\mathrm{R}_{\mathrm{e}}=\frac{\rho \mathrm{v} D_{e}}{\mu}
$$

In Eq. (3), Re is the Reynolds number, $\rho$ is the density of the alloy, $\mu$ is the viscosity of the alloy, $\mathrm{v}$ is the ingate velocity, and $D_{e}$ is the equivalent diameter of the ingate, which is defined as

$$
D_{e}=\frac{2 w t}{(w+t)}
$$

where $\mathrm{w}$ is the width and $\mathrm{t}$ is the thickness of the ingate. For a fluid flow in a closed area, a laminar flow is feasible in the range of $R_{e}<2100$, a transient flow is at $2100<R_{e}<$ 4100 , and a turbulent flow applies at $R_{e}>4100$. The parameters used for the evaluation of the Reynolds number are summarized in Table 3. The calculated results for the two types of gating systems are shown in Table $\mathbf{4}$ with various injection velocities in the range of $0.5 \mathrm{~m} / \mathrm{s}-1.5 \mathrm{~m} / \mathrm{s}$. In the case of the horizontal type, a laminar flow is expected for all injection velocities. However, for the vertical type, a transient flow pattern was expected for the injection velocity of $1.5 \mathrm{~m} / \mathrm{s}$.

The rheo-diecasting of tension arms using the new alloy was carried out for the two types of gating systems with various injection velocities. The results are shown in Fig. 6. All of the products manufactured by the horizontal type show 


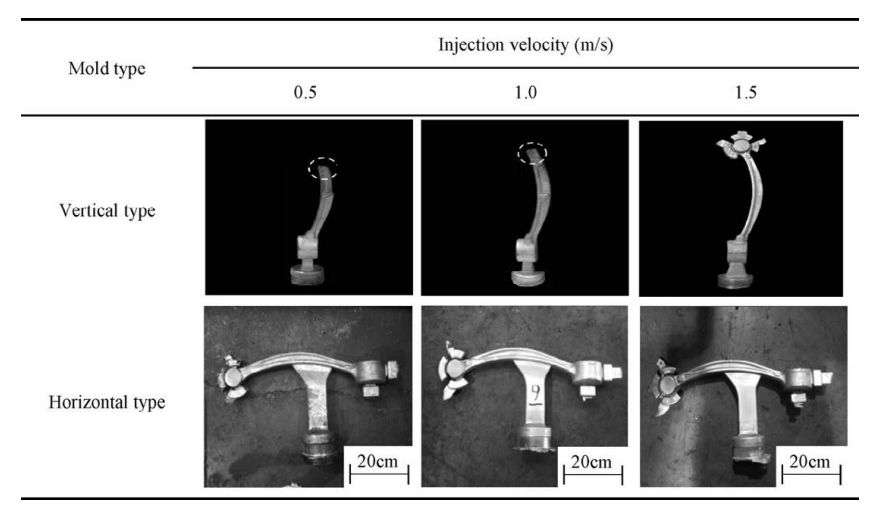

Fig. 6. Comparison between horizontal and vertical type mold at various injection velocities.

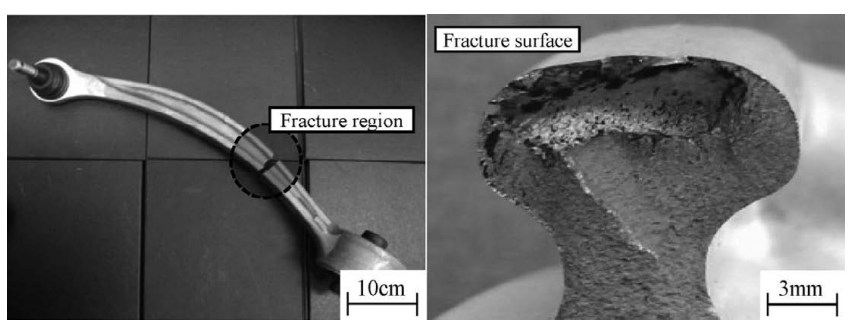

Fig. 7. Results of durability test of practical application in a verticaltype mold using an injection velocity of $1.5 \mathrm{~m} / \mathrm{s}$.

good external appearance, as expected from the Reynolds number evaluation. In the vertical-type rheo-diecast products, misrun was found with low injection velocities in the range of the laminar flow, at $0.5 \mathrm{~m} / \mathrm{s}$ and $1.0 \mathrm{~m} / \mathrm{s}$. When the injection velocity was $1.5 \mathrm{~m} / \mathrm{s}$ for the vertical type, the external appearance looks fine, though a transient flow pattern was expected. Preliminary durability tests were carried out for the rheo-diecast tension arms, showing good external appearance for three cases by the horizontal type and one for the vertical type. Among the rheo-diecast tension arms, a fracture was found in the product manufactured by the vertical type. Figure 7 shows the fracture surface of the tension arm produced by the vertical-type mold with an injection velocity of $1.5 \mathrm{~m} / \mathrm{s}$. As shown in the figure, an oxide inclusion was found on the fracture surface. This was likely caused by the transient flow pattern due to the improper mold design. However, fractures were not found from the rheo-diecast products using the horizontal-type mold. Based on these results, the horizontal-type mold was adopted for practical applications.

In the die-casting process, shrinkage defects can form in thick areas which solidify lastly. In order to solve this problem, cooling pins can be attached in thick areas. ${ }^{17)}$ Based on the mold design concept, a computer simulation of solidification during the horizontal-type rheo-diecasting was carried out to optimize the mold. These results are shown in Fig. 8. Here, (a) indicates the geometry of the product and the part to be removed by machining after rheo-diecasting, (b) denotes the shape of the final product after machining, (c) shows the results of the solidification simulation, and (d) depicts the result of an X-ray inspection of the rheo-diecast product. In this case, the section to be removed by machining after rheo-diecasting shown in (a) was attached to improve the mold filling of the semi-solid slurry during the
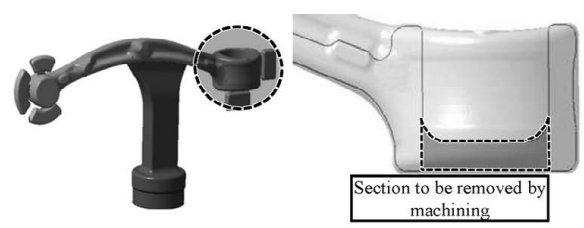

(a)

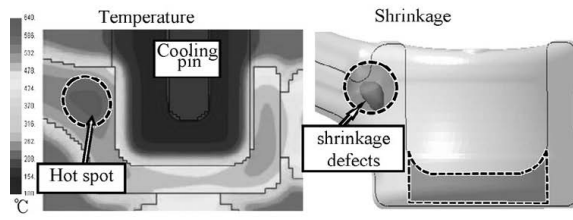

(c)

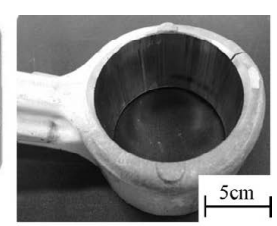

(b)

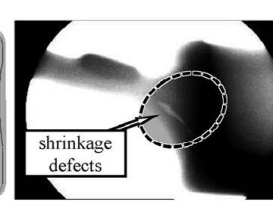

(d)
Fig. 8. Shrinkage defects at thick-wall parts; (a) initial mold design, (b) the shape of the final product, (c) simulation results of temperature and shrinkage and (d) the result of Xray analysis.

rheo-diecasting process. This part, which is not a part of the final product, will be removed by machining after rheodiecasting, as shown in (b). According to the solidification, shrinkage defects were predicted to be formed inside the product, as shown in (c). This was revealed by the X-ray inspection which was carried out on the rheo-diecast product. In order to prevent the formation of shrinkage defects in the final product, modification of the mold design using the computer simulation was carried out to improve the mold filling of the semi-solid slurry and the transfer of the casting pressure. The results are shown in Fig. 9, where (a) indicates the modified mold design, (b) shows the results of the solidification simulation, and (c) denotes the result of the $\mathrm{X}$-ray inspection. According to the simulation, the position of shrinkage defects was transferred from the section of the final products to the section which will be removed by machining after rheo-diecasting. Virtually no shrinkage defects were found in the rheo-diecast products, as revealed by the X-ray inspection results in Fig. 9(c), which are considered to have resulted from the improved mold filling and increased casting pressure. The variation of casting pressure during rheo-diecasting was not included in the fluid flow simulation model. Thus, the result of computer simulation was not completely coincident with the experimental result in this case.

The flow characteristics of semi-solid slurry in rheodiecasting are largely affected by geometrical factors such as abrupt variations in the section thickness and the direction of the flow. Casting defects such as chill formation and macro-segregation can arise in those areas. In the tension arm using the horizontal-type mold, there was an abrupt change in the section thickness around the junction between the thin ingate and the thick part of the arm, as shown in Fig. 10(a). A computer simulation of the fluid flow and the temperature field during the filling stage of the semi-solid slurry was carried out, and the results are shown in (b). As noted from the simulation, there is an isolated area around the thick area of the arm which may cause the formation of defects. A chilled region and eutectic segregation were found around this area by microstructural observation using an optical microscope, as shown in (c). The formation of eutectic segregation is considered to be caused by the fact that when the gating system is not properly designed, the 


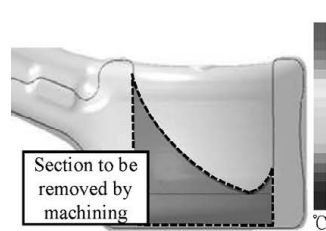

(a)

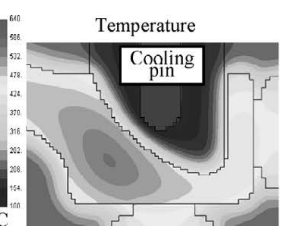

(b)

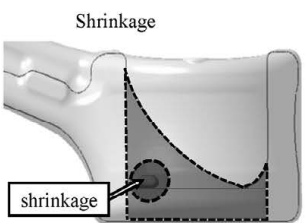

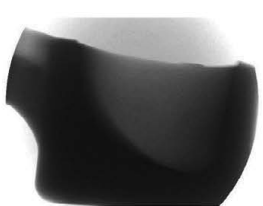

(c)

Fig. 9. Modification of the mold design for eliminating shrinkage defects at thick-wall parts; (a) modified mold design, (b) simulation results of temperature and shrinkage and (c) result of X-ray analysis.

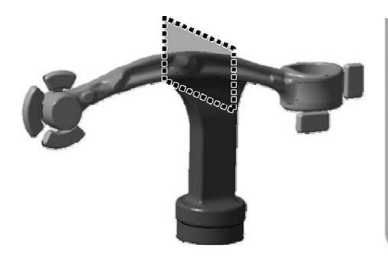

(a)

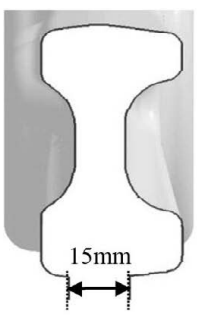

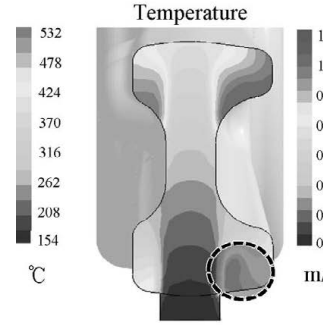

(b)

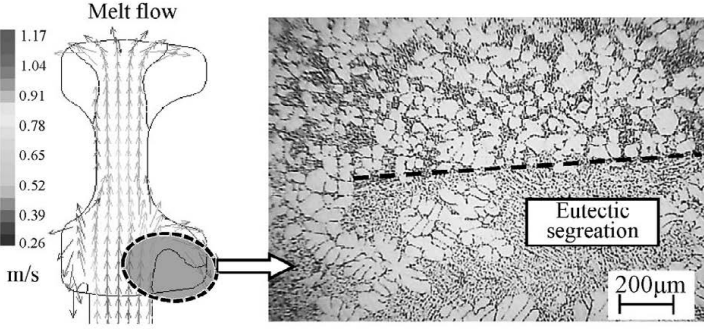

(c)

Fig. 10. Eutectic segregation defects near the ingate; (a) initial design of ingate with a width of $15 \mathrm{~mm}$, (b) simulation results of temperature and flow pattern and (c) microstructure of defects.

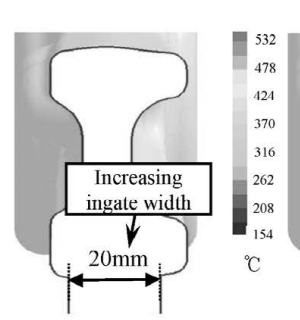

(a)

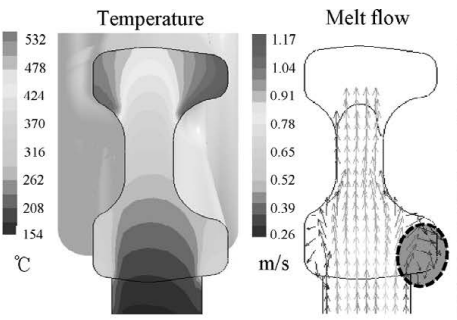

(b)

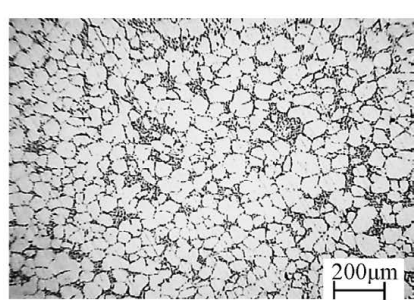

(c)

Fig. 11. Modification of the mold design for improving flow characteristics; (a) modified design of the ingate with an increased width of $20 \mathrm{~mm}$, (b) simulation results of temperature and flow pattern and (c) typical microstructure.

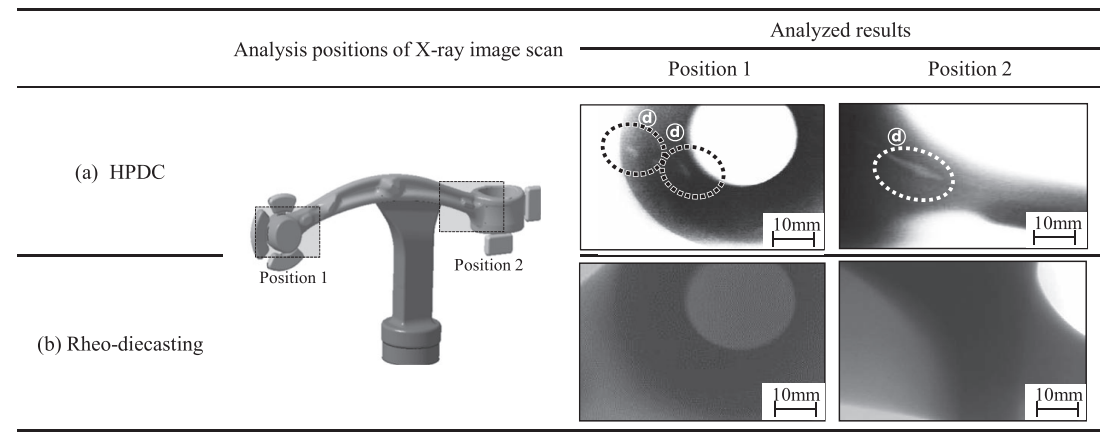

Fig. 12. The results of X-ray analyses on the tension arms; (a) HPDC process and (b) rheo-diecasting process, where "(d)" indicates shrinkage and pore defects.

remained liquid which consists of eutectic composition in the later stage of solidification, can easily flow into the region which solidifies finally, leading to the formation of eutectic segregation, as shown in the figure. This kind of eutectic segregation pattern is often found in squeeze cast- ing of Al-Si alloys. ${ }^{18)}$ In order to improve the flow pattern around this area, the ingate thickness was enlarged to 20 $\mathrm{mm}$, as shown in Fig. 11(a). A computer simulation of the flow fluid and the temperature field was carried out on the modified mold, and the results are shown in Figs. 11(b) and 
11(c). No isolated area was found around the ingate of the modified mold, and a uniform microstructure was obtained, as shown in (b) and (c).

\subsection{Practical Application of Rheo-diecasting to Auto- motive Parts}

Recently, the rheo-diecasting process was successfully applied to manufacture engine blocks, and the rheo-diecast products showed that the mechanical strength was improved by a T6 heat treatment. ${ }^{13)}$ In order to investigate the practical application of the rheo-diecasting of a high-strength Al-Si$\mathrm{Mg}$ alloy developed in a previous study, rheo-diecasting of a tension arm, which is one of the most important automobile suspension parts being produced by hot forging, was carried out using a mass production system with a 550-ton diecasting machine. The results were then compared to those by HPDC and hot forging. The modified design of the mold based on the computer simulation was adopted for the rheo-diecasting of the tension arms, and a T6 heat treatment with a solid solution treatment at $520^{\circ} \mathrm{C}$ for 6 hours and an aging treatment at $160^{\circ} \mathrm{C}$ for 5 hours were carried out.

$\mathrm{X}$-ray analyses were carried out on the final products after the T6 heat treatment to investigate the formation of casting defects. These results are shown in Fig. 12, where (a) denotes the HPDC and (b) represents the rheo-diecast results. As shown in the figure, for the tension arms manufactured by HPDC, shrinkage defects were found, as indicated by “(d)". However, for the tension arms manufactured by rheo-diecasting, no particular defects were found. A microstructural observation was carried out on the specimens created both by HPDC and rheo-diecasting after the T6 heat treatment, and the results are shown in Fig. 13, where (a) represents the HPDC and (b) the rheo-diecasting results. In the case of HPDC, the primary $\alpha$-Al phases show a dendritic morphology and segregation of eutectic $\mathrm{Si}$, as shown in (a). Furthermore, there are a number of needle-like intermetallic compounds and micro-porosities in the eutectic matrix, which are considered to be the sites of stress concentration, resulting in the deterioration of the mechanical properties. ${ }^{19)}$ However, in the case of rheo-diecasting, fine and uniform globular $\alpha$-Al particles and modified Si particles were found, which are considered to contribute to the improvement of the mechanical properties. ${ }^{20)}$ In order to estimate the uniformity of the microstructures in the rheodiecast tension arm, the rheo-diecast tension arm was cut into several sections, as shown in Fig. 14(a), and a microstructural observation was carried out using an optical microscope fitted with a digital camera and an image analyzer. Fine and uniform microstructures were obtained throughout the specimen, as shown in (b). The average diameter and the form factor of the $\alpha$-Al particles were respectively $63 \mu \mathrm{m}$ and 0.83 .

The hardness was measured after the T6 heat treatment using a Rockwell tester (HRS-150) on the specimens produced by HPDC, rheo-diecasting and hot-forging. In the cases of HPDC and rheo-casting, the new alloy was adopted, while the 6061 alloy was used for hot-forging. The measured hardness values for the three cases are shown in Fig. 15, where (a) denotes the HPDC, (b) the rheo-diecasting, and (c) the hot-forging results. The average hardness values are 55.9HRB, 64.2, and 63.1 for HPDC, rheo-diecasting, and hot-forging cases, respectively. The hardness of the rheo-diecast with the new alloy is similar to that of the hotforged product with the 6061 alloy. A tensile test was also carried out after the T6 treatment and the results were com-
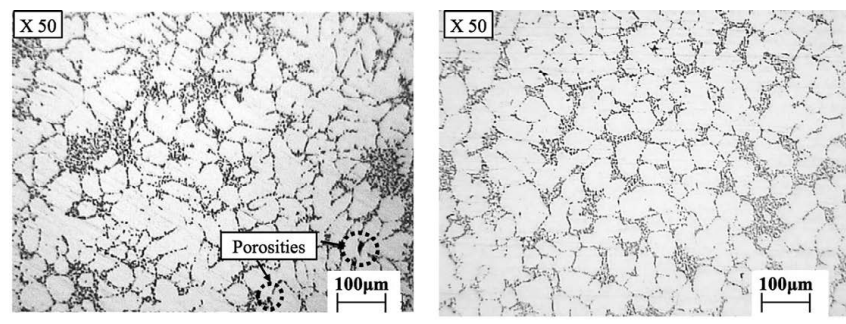

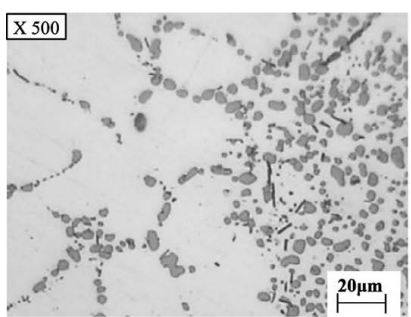

(a)

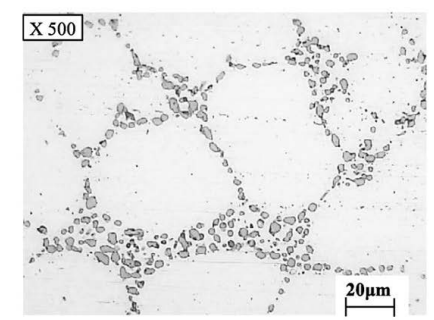

(b)
Fig. 13. Representative microstructures of the tension arms after heat treatment produced by (a) HPDC process and (b) rheo-diecasting process.

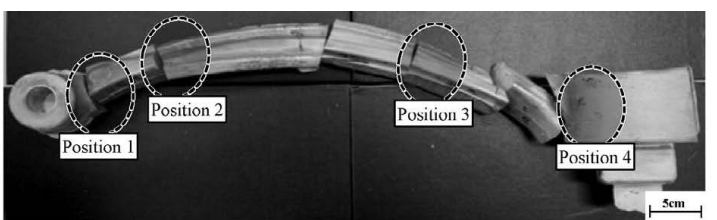

(a)

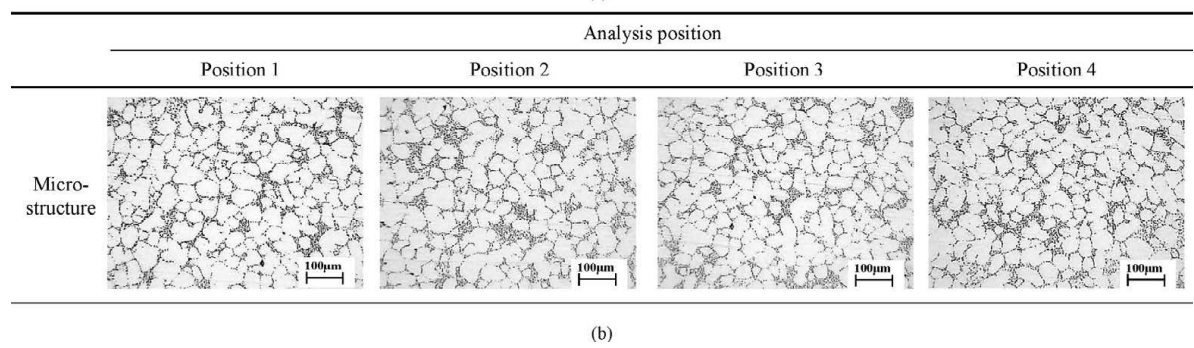

Fig. 14. Optical picture and typical microstructures of rheo-diecasting tension arm; (a) the optical picture of the tension arm and (b) typical microstructures at different positions. 
pared to those of the other manufacturing processes, as shown in Table 5. In the case of HPDC, the product shows minor elongation of less than $2 \%$ and a relatively low tensile strength compared to those by the other processes. A significant improvement in tensile properties was obtained by rheo-diecasting, with the yield strength of $281 \mathrm{MPa}$, the ten-

Table 5. Comparison of mechanical properties of the tension arms manufactured by various processes.

\begin{tabular}{|c|c|c|c|c|}
\hline & $\begin{array}{l}\text { Yield strength } \\
(\mathrm{MPa})\end{array}$ & $\begin{array}{l}\text { Ultimate tensile } \\
\text { strength (Mpa) }\end{array}$ & $\begin{array}{c}\text { Elongation } \\
(\%)\end{array}$ & Remark \\
\hline (a) HPDC & 241 & 281 & 1.2 & $\begin{array}{l}\text { The present } \\
\text { alloy }\end{array}$ \\
\hline (b) rheo-diecasting & 281 & 331 & 11.8 & $\begin{array}{l}\text { The present } \\
\text { alloy }\end{array}$ \\
\hline (c) rheo-diecasting & 237 & 293 & 11.5 & $\begin{array}{l}\text { AC4C } \\
\text { alloy }\end{array}$ \\
\hline (d) hot forging* & 285 & 322 & 11.4 & $\begin{array}{c}6061 \text { alloy } \\
\text { products }\end{array}$ \\
\hline (e) hot forging ${ }^{* *}$ & $>260$ & $>320$ & $>10$ & $\begin{array}{l}6061 \\
\text { alloy }\end{array}$ \\
\hline
\end{tabular}

\footnotetext{
* Measured values using a commercial product
}

** Specification for a commercial product sile strength of $331 \mathrm{MPa}$, and the elongation of $11.8 \%$. In addition, the rheo-diecast products of the new alloy indicate better mechanical performance, compared to those of the rheo-diecast $\mathrm{AC} 4 \mathrm{C}$ alloy. It is considered that the improvement of mechanical properties are mainly caused by several reasons such as, refinement of globular $\alpha$-Al particles, decrease of $\mathrm{Si}$ content from $7.0 \%$ to $5.0 \%$ and improvement of age hardenability by increasing the amount of $\mathrm{Mg}$ and $\mathrm{Cu}$, compared to those of AC4C alloy. The specification and the measured values of the tensile properties for hot-forged products of the $6061 \mathrm{Al}$ alloy is also shown in the table. It should be noted that the tensile properties of the rheodiecast products satisfy the specifications for commercial tension arms.

A SEM-EDS analysis of the fracture surfaces after the tensile test was carried out to investigate the fractography for both the cases of HPDC and rheo-diecasting, and the results are shown in Fig. 16. In the case of HPDC, the fractography shown in (a), indicating the cleavage fracture mode, reveals some defects, such as oxide inclusions, pores and eutectic segregation, leading to the deterioration of the tensile properties. ${ }^{21)}$ However, in the case of rheo-diecasting, there were no particular casting defects found from the

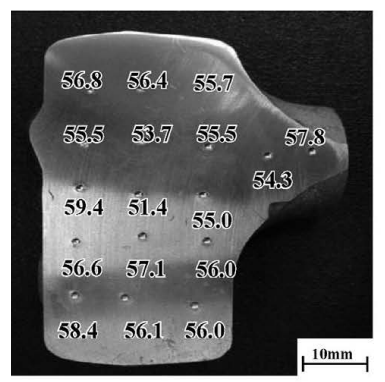

(a)

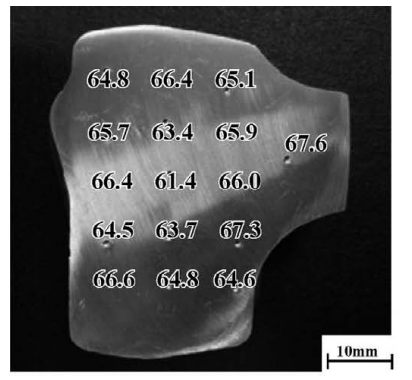

(b)

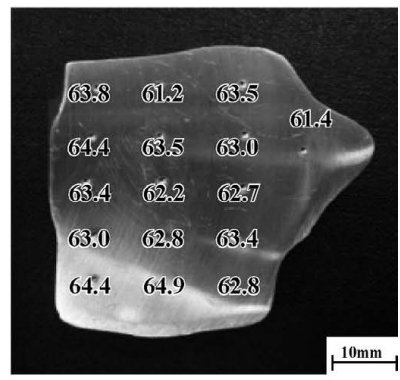

(c)

Fig. 15. The results of hardness test with various processes; (a) HPDC with developed alloy, (b) rheo-diecasting with developed alloy and (c) hot-forging with 6061 alloy(commercial product).

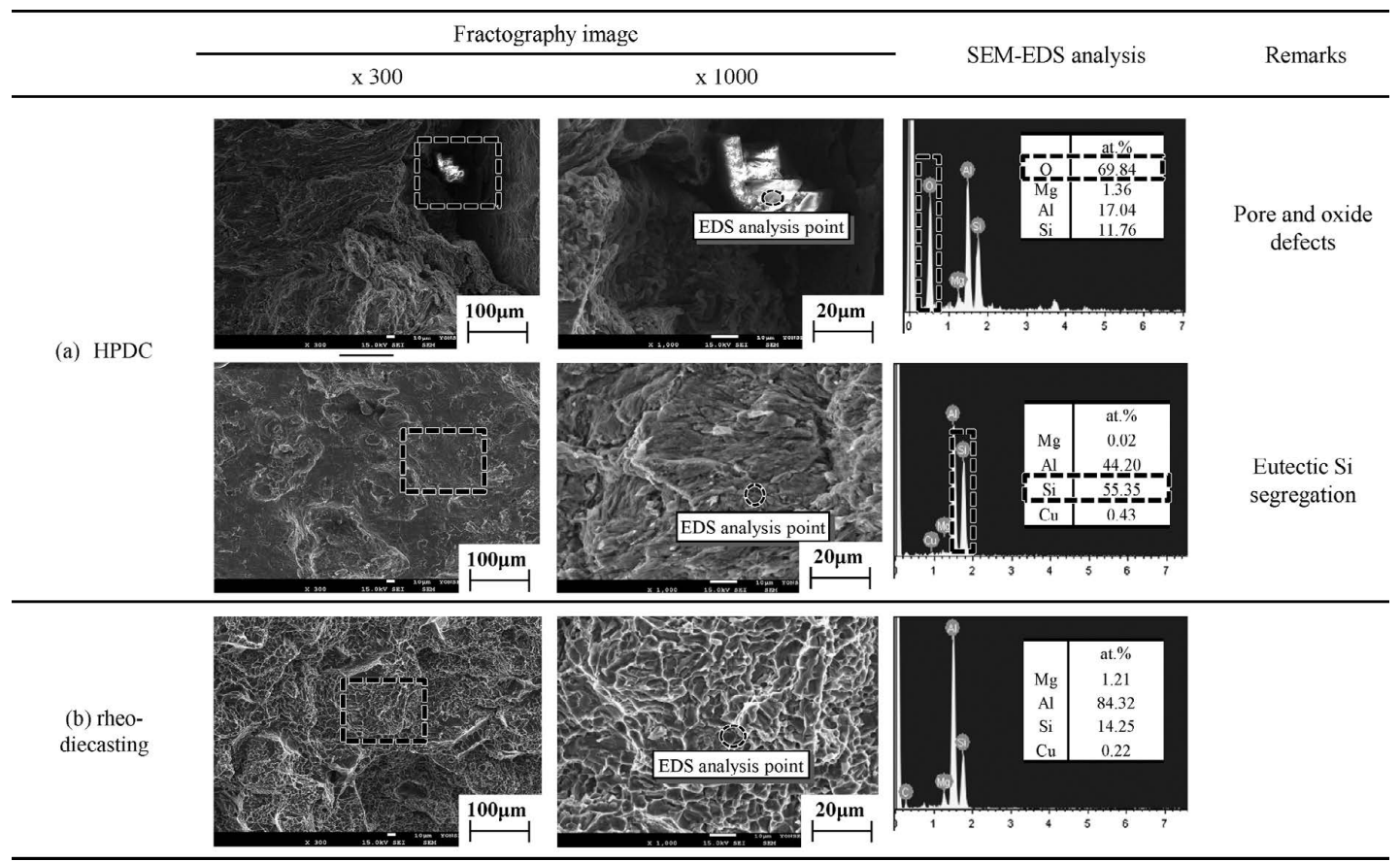

Fig. 16. The results of fractography and SEM-EDS analyses; (a) HPDC process and (b) rheo-diecasting process. 
Table 6. Results of durability and impact test; (a) tension arm durability test, (b) module durability test and (c) module impact test.

\begin{tabular}{|c|c|c|c|c|}
\hline & \multirow{2}{*}{$\begin{array}{c}\text { (a) tension arm } \\
\text { durability test } \\
\text { (number of test turns) }\end{array}$} & \multicolumn{2}{|c|}{ Assembled module test } & \multirow[b]{2}{*}{ Remark } \\
\hline & & $\begin{array}{c}\text { (b) module } \\
\text { durability test } \\
\text { (distance of test road) }\end{array}$ & $\begin{array}{l}\text { (c) module } \\
\text { impact test } \\
\text { (test load) }\end{array}$ & \\
\hline Rheo-diecasting & $\begin{array}{l}\text { No crack within } \\
1000000 \text { turns }\end{array}$ & $4500 \mathrm{~km}$ & $\begin{array}{c}\text { No crack at } \\
4829 \mathrm{kgf}\end{array}$ & \\
\hline Hot forging ${ }^{*}$ & $\begin{array}{l}\text { No crack within } \\
1000000 \text { turns }\end{array}$ & $4500 \mathrm{~km}$ & $\begin{array}{l}\text { No crack at } \\
4829 \mathrm{kgf}\end{array}$ & $\begin{array}{l}\text { Commercial } \\
\text { product }\end{array}$ \\
\hline Hot forging ${ }^{* *}$ & $\begin{array}{l}\text { No crack over } \\
500000 \text { turns }\end{array}$ & $>3000 \mathrm{~km}$ & $\begin{array}{c}\text { No crack at } \\
4829 \mathrm{kgf}\end{array}$ & $\begin{array}{l}\text { Specification for } \\
\text { commercial product }\end{array}$ \\
\hline
\end{tabular}

fracture surface, and the fractography indicates the ductilefracture mode. Finally, tension arm durability, module durability, and module impact tests were carried out on the rheodiecast tension arms in order to evaluate the possibility of the practical application of rheo-diecasting to replace the hot-forging process. These results are shown in Table 6. It was verified that all of the durability tests satisfied the specifications for the hot-forged tension arm.

\section{Conclusions}

In this study, rheo-diecasting using a high-strength Al$\mathrm{Si}-\mathrm{Mg}$ based alloy was carried out to investigate its practical application to the manufacturing of automotive suspension arms. The main results are summarized as follows:

(1) A high-quality semi-solid slurry with fine and uniform $\alpha$-Al particles using the new alloy was achieved by EM stirring and was applied to the rheo-diecasting of tension arms.

(2) A horizontal type of gating system with an injection velocity of $0.5-1.5 \mathrm{~m} / \mathrm{s}$, which was designed by a computer simulation of the fluid flow, was successfully applied to the rheo-diecasting of tension arms. No shrinkage defects and eutectic segregation were found in the final rheo-diecast products through an X-ray inspection and microstructure observations.

(3) A significant improvement in the tensile properties was obtained by rheo-diecasting, as noted by the yield strength of $281 \mathrm{MPa}$, the tensile strength of $331 \mathrm{MPa}$, and the elongation of $11.8 \%$ compared to those of the rheodiecast AC4C alloy.

(4) According to the durability test and assembled module tests, the rheo-diecast tension arms satisfied the specifications for hot-forged tension arms. It was concluded that rheodiecasting can be successfully applied to manufacture automobile suspension parts to replace the hot-forging process.

\section{Acknowledgments}

This work was supported by the Component Material Technology Development Work, the Ministry of Knowledge Economy.

\section{REFERENCES}

1) J. R. Davis: Aluminum and Aluminum Alloys, ASM International, $\mathrm{OH}, \mathrm{USA},(1993), 3$

2) R. N. Lumley, R. G. Odonnell, D. R. Gunasegaram and M. Givord: Metall. Mater. Trans. A., 38 (2007), 2564.

3) M. C. Flemings: Metall. Sci. Technol., 18 (2000), 3.

4) Z. Fan: Int. Mater. Rev., 41 (2002), 49.

5) C. P. Hong and K. D. Kim: Solid State Phenom., 116-117 (2006), 44.

6) Y. Birol: J. Alloys Comp., 470 (2009), 183.

7) J. G. Sim, J. Y. Moon, J. M. Kim and C. P. Hong: Solid State Phenom., 116-117 (2006), 509.

8) W. R. Osório, L. R. Garcia, P. R. Goulart and A. Garcia: Mater. Chem. Phys., 106 (2007), 343.

9) K. S. Park, Y. S. Jang, B. H. Choi, B. K. Kang, H. S. Kim, S. H. Choi and C. P. Hong: J. Korea Foundary Soc., 32 (2012) 98.

10) J. G. Sim, B. H. Choi, Y. S. Jang, J. M. Kim and C. P. Hong: ISIJ Int., 50 (2010), 1165.

11) J. G. Sim, J. Y. Moon, J. M. Kim and C. P. Hong: Solid State Phenom., 116-117 (2006), 44

12) S. Janudom, T. Rattanochaikul, R. Burapa, S. Wisutmethangoon and J. Wannasin: Trans. Nonferrous Met. Soc. China, 20 (2010), 1756.

13) J. G. Sim, Y. S. Jang, J. Y. Moon, J. M. Kim, K. H. Min and C. P. Hong: ISIJ Int., 49 (2009), 1700.

14) J. H. Mun, K. B. Kim, H. W. Seok, S. B. Kim and Y. D. Kim: Proc. of the 2nd Japan-Korea Conf. for Young Foundary Engineers, KITECH, Korea, (2005), 78

15) A. Ohno: Solidification - The Separation Theory and its Practical Applications, Springer-Verlag, Berlin, Heidelberg, New York, (1987), 6.

16) C. P. Hong: Computer Modeling of Heat and Fluid Flow in Materials Processing, Institute of Physics, London, (2004), 10.

17) F. Oueslati: US Patent, No. 6, 332, 770, (2001).

18) C. P. Hong, H. F. Shen and I. S. Cho: Metall. Mater. Trans. A, 29A (1998), 107.

19) N. Roy, A. M. Samuel and F. H. Samuel: Metall. Mater. Trans. A, 27 (1996), 415.

20) D. Liu, H. V. Atkinson, P. Kapranos, W. Jirattiticharoean and H. Jones: Mater. Sci. Eng. A, 361 (2003), 213.

21) K. H. Lee, Y. N. Kwon and S. H. Lee: Eng. Fract. Mech., 75 (2008), 4200 . 